\title{
O narečni osnovi jezika Celovškega ali Rateškega rokopisa ter o izvoru oblike seydi
}

\author{
Matej Šekli
}

IZVLEČEK: V članku je na podlagi obravnave značilnosti glasovnega sestava jezika Celovškega ali Rateškega rokopisa (1362-90) določena njegova genetskojezikovna pripadnost, tj. narečna osnova. Nadalje je s pomočjo filološke primerjave besedila apostolske vere $s$ starovisokonemškim izvirnikom podana tudi nova interpretacija izvora glagolske oblike seydi. Razpravi je na koncu dodana še glasovna in naglasna rekonstrukcija besedil.

ABSTRACT: This article determines the genetic-linguistic classification (i.e., the dialect base) of the Klagenfurt/Celovec Manuscript (1362-90) based on an analysis of its phonological system. Through philological comparison of the Credo text with its Old High German original, a new interpretation of the origin of the verbal form seydi is offered. Phonological and accentological reconstruction of the texts is also provided in the article.

\section{Uvod $^{1}$}

Genetskojezikoslovno opredelitev poljudnega idioma, tj. jezikovnega sistema, v nekem časovnem obdobju je mogoče podati na osnovi zgodovinskojezikoslovne interpretacije predvsem njegovega glasovnega (in oblikovnega ter manj tudi skladenjskega in slovarskega) sestava. Ker je slovenski jezik v času od Brižinskih spomenikov (972-1039) do natisa prve slovenske knjige Catechifmus In der Windifchenn Sprach (1550) Primoža Trubarja dokumentiran zelo fragmentarno, je njegovo zgodovinskojezikoslovno preučevanje v času in prostoru v starejših časovnih obdobjih precej oteženo. Zato se zgodovinsko glasoslovje (in oblikoslovje) slovenskega jezika poleg na redke poznosrednjeveške rokopisne jezikovne spomenike opira predvsem na stanje v slovenskih narečjih oz. njihovih krajevnih govorih ter na rekonstrukcijo spreminjanja slovenščine v času in prostoru. Na osnovi spoznanj narečjeslovja ter zgodovinskega glasoslovja (in oblikoslovja) slovenskega jezika 20. stoletja (Fran Ramovš (1890-1952), Tine Logar (1916-2002), Jakob Ri-

1 Besedilo je bilo pripravljeno z vnašalnim sistemom ZRCola, ki ga je na Znanstvenoraziskovalnem centru SAZU v Ljubljani (www.zrc.sazu.si) razvil Peter Weiss. 
gler (1928-1985)) je mogoče $\mathrm{v}$ glavnih obrisih nakazati, kako se je glasovna (in oblikovna) podoba slovenščine $\mathrm{v}$ času in prostoru spreminjala od alpske slovanščine (9.-10. stoletje) preko izhodiščne splošnoslovenske jezikovne stopnje (konec 12. stoletja) do sodobnih slovenskih krajevnih govorov.

V članku bo na podlagi zgodovinskojezikoslovne analize značilnosti glasovnega sestava jezika Celovškega ali Rateškega rokopisa (1362-90) ter spoznanj narečjeslovja in zgodovinskega glasoslovja slovenskega jezika 20. stoletja določena njegova genetskojezikovna pripadnost, tj. narečna osnova. Kot delni rezultat zgodovinskoglasoslovne preučitve jezika tega spomenika ter filološke primerjave besedila apostolske vere s starovisokonemškim izvirnikom bo podana tudi nova interpretacija izvora glagolske oblike seydi, ki doslej še ni dobila neproblematične razlage. Razpravi je na koncu kot sinteza obravnave dodana še glasovna in naglasna rekonstrukcija vseh treh besedil.

\section{Genetskojezikoslovna opredelitev jezika Celovškega ali Rateškega rokopisa}

Doslej je najbolj natančno genetskojezikoslovno opredelitev, tj. določitev narečne osnove jezika Celovškega ali Rateškega rokopisa podal Ivan Grafenauer: »Številčno razmerje med gorenjskimi, dolenjskimi in ziljskimi razločilnimi jezikovnimi pojavi $(7: 1: 3)$, posebno pa še med primeri za te pojave $(27: 1: 7$ [nekaj primerov za več pojavov]), do razvidnosti dokazuje, da je osnova Rateškemu rokopisu gorenjščina; predloga je bila potemtakem pisana v čisti gorenjščini s posameznim pojavom dolenjščine z Dovjega. To predlogo je prepisoval Ziljan, in sicer dokaj vestno, ker mu je ušlo v prepis le razmeroma malo ziljskih pojavov «. ${ }^{2}$ Jezik Celovškega ali Rateškega rokopisa naj bi bil torej v osnovi gorenjščina (z dolenjsko prvino, izvirajočo iz govora kraja Dovje), pri čemer pa naj bi pri prepisovanju prišlo še do vnašanja ziljskih prvin. Grafenauerjeva teorija o jezikovni mešanici jezika tega spomenika je bila v slovenistiki splošno sprejeta. ${ }^{3}$

V nadaljevanju bodo z zgodovinskojezikoslovnega vidika obravnavane glasovne značilnosti jezika Celovškega ali Rateškega rokopisa, in sicer dolgi zložniki, kratki zložniki, nezložniki. Posebej bodo obravnavane Grafenauerjeve domnevne ziljske in dolenjska posebnost. Šele na podlagi tovrstne analize bo mogoče jezik tega rokopisa opredeliti tudi genetskojezikoslovno.

\subsection{Glasovni sestav}

Glasovno gradivo Celovškega ali Rateškega rokopisa ${ }^{4}$ bo zgodovinskoglasoslovno analizirano na osnovi Logarjeve rekonstrukcije izhodiščnega splošnoslovenskega glasovnega sestava in v skladu z Logarjevo rekonstrukcijo njegovega postopnega spreminjanja do stanja, izpričanega $\mathrm{v}$ slovenskih krajevnih govorih $\mathrm{v}$ drugi polo-

2 Grafenauer 1958, 37.

3 Kot dejstvo je na primer navajana $v$ najvplivnejših slovenističnih priročnikih druge polovice 20. stoletja: Toporišič 1965, 57; 1992, 242; 1994, 39; 2000,796.

4 Prikaz glasovnega sestava Rateškega ali Celovškega rokopisa in njegova zgodovinskojezikoslovna interpretacija sta podana v Krek 1881, 179-180; Grafenauer 1958, 36-37; Mikhailov 1998, 106-107. 
vici 20. stoletja, ter na osnovi Riglerjeve rekonstrukcije spreminjanja slovenskega zložniškega sestava v času, v skladu s katero je mogoče reči, da je bilo slovensko jezikovno ozemlje v prvi polovici 14. stoletja razdeljeno na osem osnovnih narečnih baz (to so gorenjska, dolenjska, južnoštajerska, severnoštajerska, panonska, beneško-kraška, obsoško-idrijska, koroška), od katerih je imela vsaka že izoblikovan tipični zložniški sestav. ${ }^{5}$

\subsubsection{Dolgi zložniki}

Odrazi izhodiščnih splošnoslovenskih dolgih naglašenih zložnikov jezika Celovškega ali Rateškega rokopisa, na osnovi katerih ga je mogoče opredeliti genetskojezikoslovno, so naslednji: 1 . issln. $* \bar{e}>\mathrm{JV} \operatorname{sln} . * e i>\mathrm{CRR}<\mathrm{e}>\left(\mathrm{CRR}<\mathrm{re} \iint \mathrm{y}>\right.$ (I 6) $=r e s ̌ i,<$ veruyo $>$ (III 1) in <ueruyo $>$ (III 9) = ueruio, $<$ grechow $>$ (III 11) = grexou,

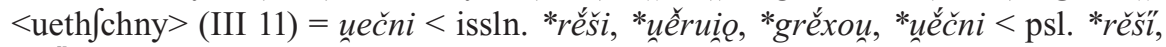

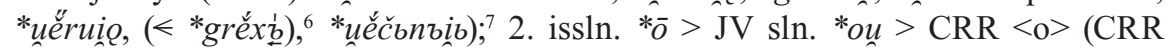
$<$ gofpod $>$ (II 1) = gospod, $<$ gofpodi $>$ (III 3) = gospodi $<$ issln. *gospôd, *gospôdi $<$ psl. *göspodb, *göspodi); 3. issln. naglašeni drugotni *ě (nastal po popsl. skrčitvi) $>$ JV sln. *ei $>$ CRR $<\mathrm{e}>\left(\mathrm{CRR}<\int l\right.$ lega $>$ (I 7) = zlega $<$ issln. *zlěga $<$ psl. $*_{\text {zblaiego }) ;}{ }^{4} 4$. issln. $* \bar{z} / * \dot{\partial}->\mathrm{Z}$ in J sln. $* \bar{a}>\mathrm{CRR}<\mathrm{a}>(\mathrm{CRR}<\mathrm{dan}>($ III 6$)=$ dan $<$ issln. *dân < psl. *dל̈nb).

Odrazi izhodiščnih splošnoslovenskih dolgih naglašenih zložnikov brez izjeme izkazujejo južnoslovensko jezikovno osnovo (issln. $*_{\bar{e}} / *_{\bar{o}}>\mathrm{JV} \operatorname{sln}$. *ei , *ou; issln. *z/*j̀- $>\mathrm{Z}$ in $\mathrm{J} \operatorname{sln} . * \bar{a})$, natančneje gorenjsko skupino, saj je v njem prišlo do t. i.

5 Logar 1981, 1974; Rigler 1963, 43-48.

${ }^{6} \mathrm{~V}$ obliki CRR grechow (III 11) = grexou je samoglasnik $e$ sicer teoretično mogoče interpretirati kot nenaglašen ali naglašen, toda glede na to, da je kakovost samoglasnika v osnovi $e$-jevska (grexou) in ne $i$-jevska (**grixou), je verjetneje, da je samostalnik naglašen na osnovi. Oblika z naglasom na končnici *grexóu bi lahko nastala iz alpskoslovanske nalikovne oblike po posplošitvi končnice in naglasa samostalnikov praslovanske $u$-jevske sklanjatve naglasnega tipa b na alpskoslovanski samostalnik praslovanskega na-

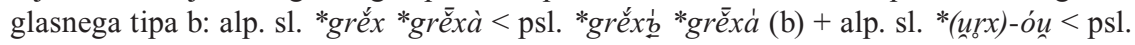
*(ubrx)-óur (po popraslovanski »zgodnji podaljšavi« praslovanskega kratkega novoakutiranega zložnika v rodilniku množine, prim. knj. sln. otrọ́k, kọnj, vọ́z, nọg < alp. sl.

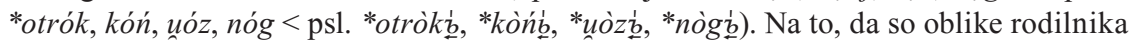
množine tipa alp. sl. *grěxou (ob oblikah tipa alp. sl. *grěx) obstajale že v času, ko je imel samostalnik še končniški naglas, tj. pred 12. stoletjem (alp. sl. *grě́x *grēxà), in da je bil opisani nalikovni vzorec možen, kažejo oblike, izpričane v Brižinskih spomenikih (<grechou> (I 10, I 11, III 21-22, III 47), <grechov> (II 113) = grěxou < greh> (I 8, I 22) $=$ grěx). Oblika rodilnika množine z naglasom na osnovi *gréxou je nalikovna po naglasu večine sklonskih oblik (issln. *grě́x *grě́xa ... < psl. *grě́x

$7 \mathrm{~V}$ besedilu torej ni izpričanih primerov odraza issln. $* \grave{e}-<$ psl. $* *_{e}-$.

8 Kot drugotni *ě skrček rekonstruira Ramovš (Ramovš 1936, 45). Na to, da gre pri skrčku $e$-jevske kakovosti za glas, ki je bil najbližji odrazu psl. *ě v slovenskih dolgih zlogih, bi kazal njegov odraz v besedilih dolenjskega narečnega tipa (SR mejga (V 14, 25, 31, 33), më̈ga $(\mathrm{V} 17,26,50)$, meyga $(\mathrm{V} 30)=$ meigga $<$ issln. *mĕga $<$ psl. *moiego $)$. Dolenjska narečna baza ima namreč za ostala dolga $e$-jevska glasova drugačen odraz (issln. $* \bar{e} / * \dot{e}$-, $* \bar{e} / *_{e}->$ dol. $* \bar{e}>$ (po 16. st.) *ie) (Rigler 1963, 44, 53; Logar 1974, [335]). 
gorenjskega tipa zgodnje monoftongizacije izhodiščnih južnoslovenskih dvoglasnikov (issln. * ${ }^{\bar{e}} / *^{2} \overline{-}-,{ }^{*} \bar{o}>\mathrm{J}$ sln. ${ }^{*} e i,{ }^{*}$ ou $>$ gor. $\left.\bar{e}, \bar{o}\right) .{ }^{9}$

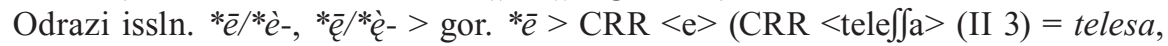

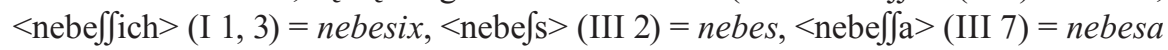

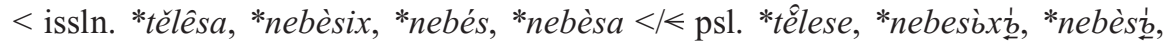
*nebesá; CRR $<$ yime $>$ (I 2) = iime, $<$ dalge $>$ (I 5) = datge, $<$ femlee $>$ (III 2) = zemle, $<$ poczett $>$ (III 3) $=$ počet,$<$ wetiga $>$ (III 4, 9) = suetiga, $<$ ralfpet $>$ (III 5) = razpet, $<$ yywe> (III 9) = žiue < issln. *(i)imê, *dtgêe, *zemlé, *počęt, *suétěga, *razpêt, *žiuê < psl. *iömę, *dôlgy, *zemlée, *pöčęt sln. $*^{\circ}-,{ }^{*} / *_{\grave{Q}}->$ gor. $*_{\bar{o}}>\mathrm{CRR}<\mathrm{0}>(\mathrm{CRR}<$ wola $>$ (I 2) = uoĺa $<$ issln. *uóla $<$ psl. *uòla; CRR $<$ body $>$ (I 1, 2) = bodi, <weemogotfchiga $>$ (III 1) = usemogočiga in CRR $<$ wemogot fchega $>$ (III 8) = usemogočaga, $<$ tody $>$ (III 8) = todi $<$ issln. *bòdi, *usemogótéga, *tódě < psl. *bọdi, *ubśemogètaiego, *tode̋̃) z izjemo JV sln. zgodnjega raznosnjenja nosnih samoglasnikov ne kažejo sprememb.

Odraza naglašenih in nenaglašenih issln. ${ }^{*} r>\mathrm{CRR}<$ ar, or $>*$ [ər] (CRR $<$ martaw $>$ (III 5) $=$ martau, $<$ martwech $>$ (III 7) $=$ martuax $;<$ mortwe $>$ (III 9) $=$ martue $<$ issln. *mítau, *mrtuè * *mítuix < psl. *mb́rtubi, *mbrtuý, *mb́rtuъibxb) in issln. *t > CRR $<$ al, all $>*$ [əł] (CRR <dalge $>$ (I 5) $=$ dətge, $<$ dalnykom $>$ (I 5) $=$ dək $\langle\check{z}\rangle$ nikom, $<$ pall-

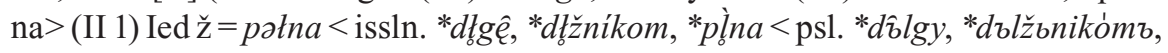
*pb̆lna) kažeta na razpad issln. zlogotvornega zvočnika na polglasnik $a$-jevske barve (ki se ob nosnem soglasniku približuje $o$-jevski barvi) in zvočnik. Odraz issln. kratkega naglašenega in nenaglašenega * ne v položaju ob zvočnikih $r$ in $l$ je bil tudi $a$-jevske barve (v položaju za trdonebnikom pa se je približeval $e$-jevski barvi) $\left(\mathrm{CRR}<\right.$ danna $\int \mathrm{s}>$ (I 4) $=$ donəs, $<$ paklu $>$ (III 6) $=$ pəktu, $<$ Cze $\int \mathrm{t}$ chena $>$ (II 1) $=$

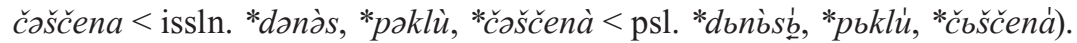

\subsubsection{Kratki zložniki}

Odrazi južnoslovenskih kratkih, tj. izhodiščnih splošnoslovenskih kratkih naglašenih zložnikov v edinem besednem zlogu in nenaglašenih zložnikov jezika Celovškega ali Rateškega rokopisa, na osnovi katerih ga je mogoče opredeliti genetskojezikoslovno, so naslednji: 1. issln. $*_{-} \grave{e} / *^{2}>\mathrm{CRR}<\mathrm{i}, \mathrm{y}>*$ [i] (CRR $<$ gori $>$ (III 6) in $<$ Gory $>$ (III 7) = gori, $<$ tody $>$ (III 8) $=$ todi, $<$ divittcze $>$ (III 4) $=$ diuice $<$ issln.

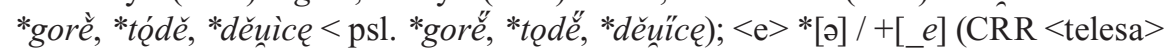

9 Rigler 1963, 50-51; Logar 1974, [335].

${ }^{10}$ Izhodiščne splošnoslovenske nalikovne zamenjave praslovanskih končnic so naslednje: 1. Red soglasniške sklanjatve z Red $o$-jevske sklanjatve (psl. *te̊lese $\rightarrow$ issln. *tělêsa); 2. Mmn soglasniške sklanjatve z Mmn mehke $o$-jevske sklanjatve (psl. *nebes *nebèsix); 3. trda končnica Tmn moške $o$-jevske sklanjatve in Tmn m zložene pridevniške sklanjatve z mehko končnico (psl. *db̂lgy, *žîuy $>$ issln. *dtgệ, *žiuêe); 4. Red $a$-jevske sklanjatve z Red zaimenske sklanjatve (issln. ${ }^{*}-\dot{e}<$ psl. *-oię ${ }^{*}$-eiè po skrčitvi) (psl.

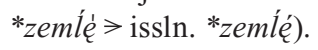

Izhodiščni splošnoslovenski naglasni nalikovni spremembi sta naslednji: naglas prvotnih oblike psl. *nebesá, *nebesb̀x $\underline{\underline{b}}$ je posplošen po naglasu Mmn $o$-jevske sklanjatve naglasnega tipa c (psl. novoakutski tonem na osnovi). 
(I 3) = telesa/talesa $<$ issln. *tělêsa $<$ psl. *têlese) $;{ }^{11} 2$ 2. issln. nenaglašeni drugotni *ě (nastal po popsl. skrčitvi in issln. skrajšan v ponaglasnem zlogu) $>\mathrm{CRR}<\mathrm{i}>$

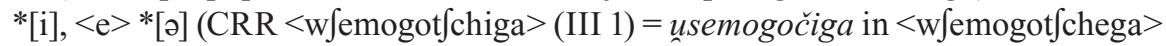
$($ III 8) = usemogočəga,$<$ wetiga $>$ (III 4, 9) = suetiga (edyniga (III 3) = ediniga, naffiga (III 3) = našiga s končnico CRR -iga, ki odraža issln. končnico pridevniške sklanjatve, tj. psl. zložene pridevniške sklanjatve) < issln. *usemogótéga, *suę́těga $<$ psl. *ubśemogétaieno, *suętaiego); 3. issln. *-ò/*o $>\mathrm{CRR}<\mathrm{u}>(\mathrm{CRR}$

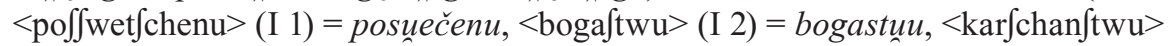
(III 10) = krršanstuu $<$ issln. *posuętenò, *bogâtstuo, *krbščânstuo $<$ psl. *posuętenó, *bogätbstuo, *krbščannbstuo), CRR <0> / +[m_] (CRR odpuffchamo (I 5) < issln. *odpúščamo < popsl. *odpuščâmo < psl. *odpuščăiemo).

Odrazi kratkih, tj. kratkih naglašenih in nenaglašenih zložnikov tudi kažejo na južnoslovensko osnovo, natančneje gorenjsko skupino (issln. $*_{-} \grave{e} / *^{2} \check{>}>i$, issln. $*_{-} \grave{u}$ $>u$; prišlo je do izgube naprej pomaknjenega izgovora JV $\operatorname{sln} .{ }^{*} \dot{u}<$ issln. $\left.{ }^{*} u\right) .{ }^{12}$ Stopnja sodobnega samoglasniškega upada je nizka (issln. ${ }^{*} o>u$; issln. $i$ in issln. $u$ sta večinoma še ohranjena), najverjetneje pa je opaziti začetek delnega reduciranja gor. $*_{i}\left(<\right.$ issln. $\left.*_{i} / *_{e}\right)>\mathrm{CRR}<\mathrm{e}>*$ [ə] (CRR naffen (I 5) = našzn, $<$ martwech $>$ (III 7) $=$ martuəx,$<$ wemogot $\int$ chega $>($ III 8$)=$ usemogočaga $) .^{13,14}$

\subsubsection{Nezložniki}

V sestavu nezložnikov je za genetskojezikoslovno opredelitev jezika rokopisa pomemben zlasti začetek procesa poenostavljanja issln. soglasniškega sklopa *šč, saj se pojavljajo dvojni odrazi (nepoenostavljeni in poenostavljeni soglasniški sklop):

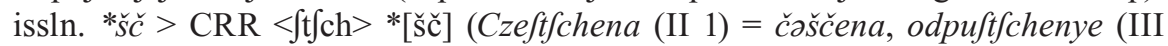
10) = odpuščenie); CRR $<\iint \mathrm{ch}, \int \mathrm{ch}>*[\check{\mathrm{s}} \mathrm{s}] / *[\check{\mathrm{s}}]($ odpuffchamo (I 5) = odpušamo, karfchanftwu (III 10) = kəršanstuuu). ${ }^{15}$ Tudi ta značilnost soglasniškega sestava kaže na to, da je osnova jezika rokopisa gorenjska.

${ }^{11}$ Obliko CRR <telesa> je teoretično mogoče brati kot təlesa ali kot telese. Oblika təlese $\mathrm{z}$ CRR *ə< issln. *ě bi kazala pojav zgodnjega (delnega) sodobnega samoglasniškega upada gor.-dol. $*_{i}<$ issln. $* \check{e}$, tj. pričakovanega $i$-jevskega odraza issln. nenaglašenega $*_{e} \mathrm{v}$ osrednjih slovenskih narečjih. Obliko telese z CRR *e $<$ issln. *ě je mogoče razložiti kot odraz delnega samoglasniškega sozvočja, tj. spremembo odraza issln. *̌e v e v položaju pred $e$ (Rigler 1963, 36-37).

${ }^{12} \mathrm{~V}$ dolenjski skupini do izgube naprej pomaknjenega izgovora JV $\operatorname{sln}$. ${ }^{*} \dot{u}<$ issln. ${ }^{*} u$ ne pride, poleg tega pa pride še do spremembe JV sln. nenaglašeni $\dot{u}>i$ (Logar 1974, [334])

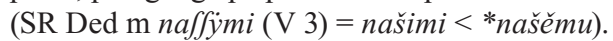

${ }^{13}$ Po novejših odkritjih na osnovi srednjeveških rokopisov je mogoče tudi v tržaški slovenščini začetek pojava sodobnega samoglasniškega upada postaviti v 14. stoletje (Merkù 1983).

${ }^{14}$ Zapisi CRR in SGR $<$ e $>$ za issln. $*_{e} / *_{i} i$ predstavljajo redukcijo prvotnega $*_{i}<$ issln. $*_{e} / *_{i} i$, pri čemer glasovna vrednost reduciranega samoglasnika ni nujno polglasniška, lahko gre namreč za redukcijo $*_{i}>*_{e}$, ki je danes na primer značilna za narečja na slovenskem zahodu (Furlan 2007, 304; Metka Furlan, ustno).

${ }^{15}$ Zapis $<\iint \mathrm{ch}, \int \mathrm{ch}>$ se interpretirana bodisi kot zapis nepoenostavljenega soglasniškega sklopa šč (Ramovš 1924: 280) bodisi kot domnevni zapis poenostavljenega soglasniškega $\check{s}$ (Grafenauer 1958, 37; Mikhailov 1998, 107). 


\subsection{Domnevne ziljske glasovne posebnosti}

Jezik Celovškega ali Rateškega rokopisa pa naj bi izkazoval tudi naslednje tri ziljske glasovne posebnosti: 1 . samoglasnik -e- (in ne -i-) v končnicah Rmn pridevnika (CRR <martwech> (III 7)) in Dmn svojilnega zaimka za prvo osebo množine

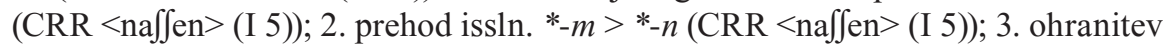
soglasniške skupine $\check{s} \check{c}$ (za razliko od gorenjskega $\check{s}$ ). ${ }^{16}$

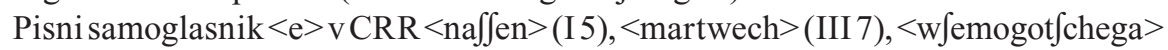
(III 8) je mogoče brati tudi polglasniško (tj. našวn, mərtuðx, usemogočaga), kar bi pomenilo, da jezik izkazuje posamezne primere, tj. začetno stopnjo sodobnega samoglasniškega upada. ${ }^{17}$ Edini izpričani primer prehoda issln. ${ }^{*}-m>*_{-} n$ v CRR

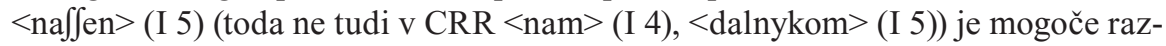
lagati tudi $\mathrm{v}$ okviru izgovora $\mathrm{v}$ sandhiju, prvotni izglasni *-m se namreč pojavlja $\mathrm{v}$ položaju pred zobnikom $d\left(\mathrm{CRR}<\right.$ my odpu $\iint$ chamo na $\iint e n$ dalnykom $>$ (III 5) $=$ mi odpušamo našan dał $\langle\check{z}\rangle$ nikom).$^{18}$ Dvojnost odrazov issln. soglasniške skupine *šč je mogoče pripisati dejstvu, da je bil v gorenjščini v drugi polovici 14. stoletja proces poenostavljanja issln. ${ }^{*} \check{S} \check{c}>$ gor. $\check{S}$ na začetni stopnji. ${ }^{19}$

${ }^{16}$ Grafenauer 1958, 32-33.

${ }^{17}$ Precej večjo stopnjo sodobnega samoglasniškega upada izkazuje Starogorski rokopis (1492-98), katerega narečna osnova je tudi gorenjska: issln. $*_{i}>\mathrm{SGR}<\mathrm{e}>*[ə](<$ yeme $>$

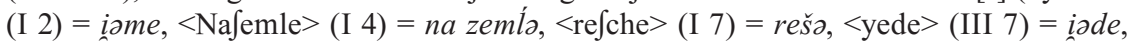
$<$ trettye $>$ (III 8) = tretiza, $<$ Smertte $>$ (III 9) $=$ smartə, $<$ chewotta $>$ (III 15) $=$ žzuota; SGR $<\varnothing>*[ə],[\varnothing](<$ toppl $>$ (III 9) = stopal, od tod (III 9-10)). Na osnovi sicer skopega gradiva Celovškega ali Rateškega in Starogorskega rokopisa je torej mogoče sklepati, da se je sodobni samoglasniški upad issln. $*_{i} / *_{e}$ v gorenjščini začel pojavljati v drugi polovici 14. stoletja (posamezni primeri issln. $*_{i} / *_{e}>\mathrm{CRR} *_{\partial}$ ), razmahnil pa naj bi se v 15 . stoletju (večina primerov issln. $*_{i} / *^{2} \check{e}>\mathrm{SGR} *$, posamezni primeri issln. $*_{i} / *_{e}>\mathrm{SGR} *_{\varnothing}$ ).

${ }^{18}$ Vzrok za različno odražanje izglasnega $*-m$ v položaju pred zobnikom $d$ v sandhiju $\mathrm{v}$

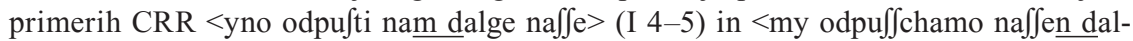
nykom $>$ (III 5) je morda v ritmu govora. V prvem primeru je nam zaslonka in se izgovorno naslanja na predhodni glagol in ne na sledečo zloženo samostalniško besedno zvezo, v drugem primeru je našzn ujemalni prilastek, ki se pojavlja pred svojim določilom, na katerega se izgovorno tudi naslanja. Členitev analiziranih besedilnih odsekov na izgovorne enote bi tako lahko bilo naslednje: kakor ino mi / odpušamo / našon dał 〈̌̌ $\rangle$ nikom ino odpusti nam / dałge naše.

Da je bilo premenjevanje fonemov $/ \mathrm{m} /$ in $/ \mathrm{n} / \mathrm{v}$ sandhijevskem položaju nekoč razširjeno na širšem arealu kot danes, zgovorno pričajo zabeležbe s slovenskega zahoda, kjer je zgodovinsko izpričan tudi prehod /n/ v/m/, npr. v Alasijevem slovarju iz leta 1607 (adam 'vno', vum 'fuora', dam 'giorno', sim 'figliuolo') in v jezikovnem gradivu Baudouina de Courtenaya iz druge polovice 19. st. (Škrátec am máslar) (Furlan 1991, 26).

${ }^{19}$ Končno stopnjo prehod issln. ${ }^{*} \breve{s} \check{c}>$ gor. $\check{s}$ izkazuje jezik Starogorskega rokopisa: issln. ${ }^{*} i$ $>\mathrm{SGR}<\int \mathrm{ch}>*[\check{\mathrm{s}}]\left(<\right.$ Zhe $\int \mathrm{chena}>$ (II 1) = čวšena, $<$ kher $\int \mathrm{chan} \int \mathrm{ckho}>$ (III 14) = karšansko, $<$ odpufchane $>($ III 15) $=$ odpušanie $)$. Na osnovi sicer skopega gradiva Celovškega ali Rateškega in Starogorskega rokopisa je torej mogoče reči, da je prehod issln. * ${ }_{s} \breve{c}>$ gor. $\check{s}$ začel pojavljati v drugi polovici 14. stoletja (dvojnost odrazov), dokončal pa naj bi se v 15. stoletju (vsi izpričani primeri imajo odraz s poenostavljenim soglasniškim sklopom). 


\subsection{Glagolska oblika seydi kot domnevna dolenjska glasovna posebnost}

Dolenjska posebnost (govora kraja Dovje) v jeziku Celovškega ali Rateškega roko-

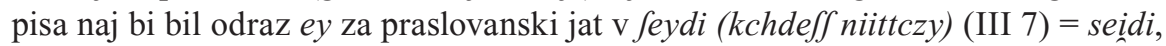
sicer napačno zapisana oblika 3. osebe ednine aorista za pričakovano *eyde, pri čemer naj bi aorist posredno potrjevali obliki stvn. gisaaz ci cesuûn v Weißenbruškem obrazcu apostolske vere in stcsl. cłaє • дєсмож V Sinajskem evhologiju. ${ }^{20}$

Oblika stvn. <gisaaz> = gisaz je 3. oseba ednine preterita stvn. glagola gisizzen 'sedeti, sesti' (Braune-Eggers 1987: 282; Schützeichel 1995: 253), ${ }^{21}$ glagola stanja in gibanja. Oblika stcsl. ck_t je 3. oseba ednine krepkega aorista glagola stcsl. сћсти садєши 'sesti' (Babič 2003, 162, 182; SS: 679), glagola gibanja. Zelo verjetno je, da oblika feydi v Celovškem ali Rateškem rokopisu odraža obliko 3. osebe ednine sigmatičnega aorista glagola psl. *sěděti *sědíšb 'sedeti', stcsl. cłatти съдиши 'sedeti' (Babič 2003, 172, 184; SS, 678-679) (CRR feydi< issln. *sĕdě< psl. *sědĕ 'sedèl je', stcsl. ckAt 'sedèl je', kar bi pomenilo, da je CRR ei pričakovani odraz issln. dolgega naglašenega *̌e, CRR $i$ pa pričakovani odraz issln. nenaglašenega, tj. kratkega *ě), za slovenščino v tem kontekstu neobičajno rabo vrste glagolskega dejanja (glagol stanja namesto glagola gibanja) pa je mogoče pripisati oblikoskladenjskemu vplivu starovisokonemškega izvirnika. ${ }^{22}$ Odraz CCR $e i{ }^{2}<$ issln. *ě je verjetno ostanek nepoenoglašenega dvoglasnika JV sln. *ei $<$ issln. *ěe, ki je kot arhaizem ohranjen tudi v nekaterih obrobnih gorenjskih govorih (govor krajev Dovje in Mojstrana ter govori osrednje Tuhinjske doline). ${ }^{23}$ Ohranitev dvoglasnika ei je mogoče pripisati oblikovni izoliranosti arhaične aoristne oblike, ki v drugi polovici 14. stoletja v narečjih najverjetneje ni bila več v rabi. ${ }^{24}$

\section{Glasovna in naglasna rekonstrukcija jezika Celovškega ali Rateškega roko- pisa}

Levo je podan diplomatični prepis besedil Celovškega ali Rateškega rokopisa, pov-

${ }^{20}$ Grafenauer 1958, 36.

${ }^{21}$ Za glagol stvn. gisizzen se v germanističnih priročnikih navajajo naslednji pomeni: sitzen, sich (auf)setzen, sich niederlassen; besitzen, haben (Schützeichel 1995, 253).

${ }^{22}$ V Celovškem ali Rateškem rokopisu je še več skladenjskih kalkov po stari visoki nemščini, npr. raba krajevnih prislovov ob glagolih gibanja: CRR dolu iide $k$ pəktu $=$ stvn. nidhar steig ci helliu; CRR gori iiide u nebesa $=$ stvn. üf steig ci himilon (starovisokonemško gradivo je navajano po Janko-Teržan-Kopecky 2000, 17).

${ }^{23}$ Logar 1954, [42]; 1962/63, 3; Rigler 1963, 50-51. Tako je odraz ey v seydi interpretiran tudi v Toporišič 1992, 242.

${ }^{24} \mathrm{Na}$ neživost aoristnih oblik v slovenščini poznega srednjega veka bi kazala tudi njegova skoraj popolna odsotnost v kasnejših rokopisnih spomenikih. V besedilu Starogorskega rokopisa se na primer aorist pojavlja samo enkrat (CRR dolu yide kchpaklu (III 6), SGR pred peckhell yede (III 8), sicer pa se na mestu njega pojavlja bodisi perfekt (CRR na trettyi dan gori wstaa od martwech (III 6-7) SGR Na trettye dan od Smertte vftall (III 8-9); CRR Gory yiede wnebeffa (III 7) SGR Na nebw ftoppl (III 9)) bodisi prezent

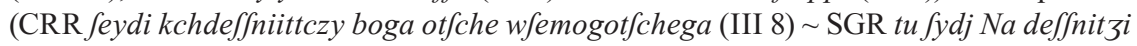
Swoyga otzcha nebefkhiga (III 9-10)). 
zet po dosedanjih prečrkovanjih, ${ }^{25}$ desno pa glasovna in naglasna rekonstrukcija besedil, ki je $\mathrm{v}$ rekonstrukciji glasovja $\mathrm{v}$ precejšnji meri, $\mathrm{v}$ rekonstrukciji naglasa pa povsem avtorska. ${ }^{26}$

Pri rekonstrukciji naglasnega sestava so bila upoštevana spoznanja slovenskega zgodovinskega naglasoslovja,${ }^{27}$ dopolnjena s spoznanji slovanskega (zgodovinsko) primerjalnega naglasoslovja druge polovice 20 . stoletja. ${ }^{28}$ Edina nesplošnoslovenska naglasna sprememba, do katere je najverjetneje prišlo $\mathrm{v}$ času od t. i. izhodiščnega splošnoslovenskega naglasnega sestava (12. st. $)^{29}$ do jezika Celovškega ali Rateškega rokopisa (2. pol. 14. st.) je bilo zahodno- in južnoslovensko zgodnje daljšanje kratkih akutiranih samoglasnikov v nezadnjih besednih zlogih, in sicer tako $\mathrm{v}$ predzadnjih kot $\mathrm{v}$ predpredzadnjih (13./14. st.) (tj. nesplošnoslovensko daljšanje tipa issln. *kràua $>\mathrm{Z}$ in J sln. *kráua.$^{30}$ Do na primer nesplošnoslovenskega umika naglasa s slovenskega odprtega (in zaprtega) kratkega (cirkumflektiranega) končnega (tj. psl. kratkega ali popsl. skrajšanega psl. dolgega) zložnika na prednaglasno kračino (tj. psl. kračino ali popsl. skrajšano psl. dolžino) (od 15. st. naprej) (tj. nesplošnoslovenski naglasni umik tipa issln. *ženà, *kozà > nespl. sln. *žèna, *kòza) naj bi v obravnavanem času še ne bilo prišlo. ${ }^{31}$

Diplomatični prepis

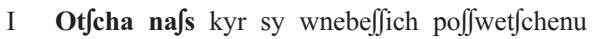
body twoye yime pridi bogaftwu twoye body wola

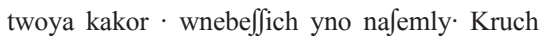
nafs

wedanny day nam dannafs yno odpufti nam

5 dalge na $\int$ e kakor yno my odpu $\iint$ chamo na $\iint e n$ dalnykom

yno nafs ne wuppellay wednero y $\iint k u \int b o$ le nafs refey ob

odflega· amen.
Glasovna in naglasna rekonstrukcija

Očä näš, kir sî un nebésix, posưečenü bódi

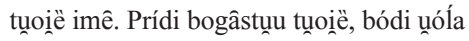
tụoiä, kakôr un nebésix ino na zemílì. Krüx näš unsedánńi däi nam dənə̈s ino odpústi nam dəłgê náše, kakôr ino mî odpúšamo nášən dəł<̌̌>níkom,

ino nas ne upeläi un ednêro izkûsbo, lë nas réši od zléga.

${ }^{25}$ Dosedanja prečrkovanja so naslednja: Grafenauer 1942, 32; Toporišič 1981, 406; Mikhailov 1998, 95, 98, 99; 2001, 79-80. Upoštevano je bilo zadnje prečrkovanje v Mikhailov 1998 in 2001.

${ }^{26}$ Dosedanji glasovni prepisi so naslednji: Grafenauer 1942, 32; Toporišič 1981, 406; Mikhailov 1998, 95, 98, 99-100; 2001, 79-81. Odstopanja od dosedanjih prepisov posebej ne navajam.

${ }^{27}$ Ramovš 1950; Rigler 1970, 1971, 1977, 1978.

${ }^{28} \mathrm{~V}$ prvi vrsti njegovega osrednjega in standardnega, $\mathrm{tj}$. »oblikoslovnega« metodološkega pristopa (ob upoštevanju »glasoslovnega«), ki se pojavlja v delu Christiana S. Stanga Slavonic accentuation (Stang 1957) ter v iz njega izhajajočih delih avtorjev moskovske naglasoslovne šole od naglasoslovnih objav Vladimira Antonoviča Dyboja (od leta 1958) (Дыбо 1981, 2000).

${ }^{29}$ Logar 1981.

${ }^{30}$ Ramovš 1950, 18, 23.

${ }^{31}$ Ramovš 1950, 18, 23. 


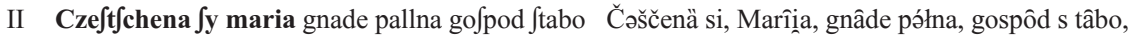

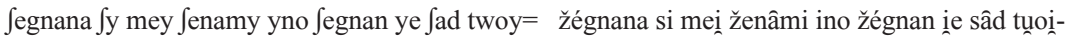
ga tele $\iint \mathrm{a}$ ihs xps amen. gä telêsa, Íćžuš Krîštuš.

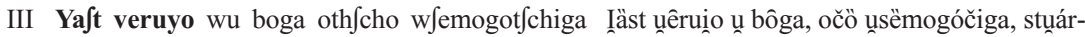
ftwar

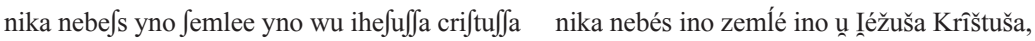

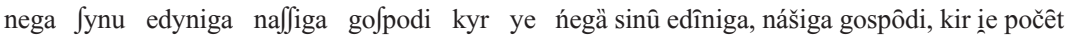
poczett od fwetiga ducha royen ys dívittcze marie od suétiga duxâ, roinèn iz diứce Marîie, mârtran Martran pod pod

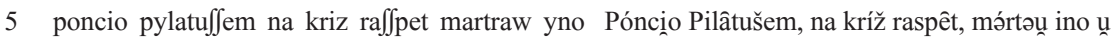
wu

grab polofen dolu yide kchpaklu na trettyi dan grâb položěn. Dołü iidê k pəkłü, na trétini dân gori gorì

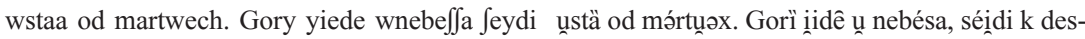
kchde $\iint$

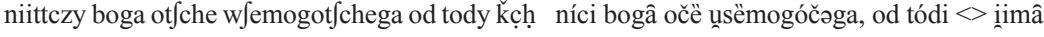
iyma

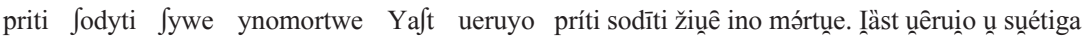
wufwetiga

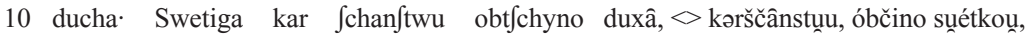
fwettkow

odpuft fchenye grechow wftanye ziwota yno odpuščénie gréxoun, unstânie žiunotä ino unéčni ueth chny

leben amen. lêbən.

\section{Zaključek}

Glasovni sestav jezika Celovškega ali Rateškega rokopisa (1362-90) izkazuje značilnosti gorenjske narečne baze: 1. v sestavu dolgih zložnikov je prišlo do t. i. gorenjskega tipa zgodnje monoftongizacije izhodiščnih jugovzhodnih slovenskih dvoglasnikov (z ohranjenim dvoglasnikom ei v oblikovno izolirani arhaični obliki aorista $<$ seydi $>$ ): issln. $*^{\bar{e}} / *^{*} \bar{o}>\mathrm{JV} \operatorname{sln} .{ }^{*} e \mathrm{i} / *_{\text {ou }}>\mathrm{CRR}<\mathrm{e}>/<\mathrm{o}>$; 2 . v sestavu kratkih zložnikov je opaziti začetno stopnjo t. i. slovenskega sodobnega samoglasniškega upada: issln. ${ }^{*} o>\mathrm{CRR}<\mathrm{u}>$; issln. $*_{i} / *^{*}>\mathrm{CRR}<\mathrm{i}, \mathrm{y}>*[\mathrm{i}],<\mathrm{e}>*[ə] ; 3 . \mathrm{v}$ soglasniškem sestavu je opazen začetek procesa poenostavljanja issln. soglasniške-

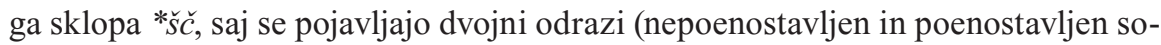
glasniški sklop): issln. * *̌š $>\mathrm{CRR}<\int \mathrm{t} \int \mathrm{ch}>*[\check{\mathrm{s}} \check{c}],<\iint \mathrm{ch}, \int \mathrm{ch}>*[\check{\mathrm{s}} \check{\mathrm{s}}] / *[\check{\mathrm{s}}]$. Domnevne ziljske in dolenjsko glasovno posebnost je mogoče razlagati tudi v okviru gorenjščine, kar postavlja pod vprašaj Grafenauerjevo teorijo o narečni mešanici jezika tega spomenika.

Glagolska oblika CRR $<$ eydi $>$ odraža obliko 3. osebe ednine sigmatičnega aori-

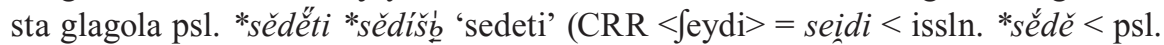
*sědĕ 'sedèl je'), za slovenščino v tem kontekstu neobičajno rabo vrste glagolskega 
dejanja (glagol stanja namesto glagola gibanja) pa je mogoče pripisati oblikoskladenjskemu vplivu starovisokonemškega izvirnika (stvn. gisaz 'sedèl je; sédel je').

\section{Kratice, krajšave, posebni znaki}

alp. sl. $=$ alpskoslovanski, alpska slovanščina; $\mathrm{BS}=$ Brižinski spomeniki; $\mathrm{CRR}=$ Celovški ali Rateški rokopis; dol. = dolenjski, dolenjsko narečje, dolenjščina; gor. = gorenjski, gorenjsko narečje, gorenjščina; issln. = izhodiščni splošnoslovenski; $\mathrm{JV}=$ jugovzhodni; knj. = knjižni; popsl. = popraslovanski; psl. = praslovanski, praslovanščina; $\mathrm{SGR}=$ Starogorski rokopis; sln. = slovenski, slovenščina; $\mathrm{SR}=$ Stiški rokopis; $x>y$ ( $x$ se spremeni $\mathrm{v} y$ po glasovni/naglasni spremembi); $x<y(x$ nastane iz $y$ po glasovni/naglasni spremembi); $x>y$ ( $x$ se spremeni $\mathrm{v} y$ po nalikovni spremembi); $x<y$ ( $x$ nastane iz $y$ po nalikovni spremembi); issln. $* \bar{V}=$ izhodiščni splošnoslovenski dolgi samoglasnik; issln. $* \dot{V}-=$ izhodiščni splošnoslovenski kratki naglašeni samoglasnik v nezadnjem besednem zlogu; issln. $*_{-} \grave{V}=$ izhodiščni splošnoslovenski kratki naglašeni samoglasnik v edinem/zadnjem besednem zlo$\mathrm{gu}$; issln. $* V=$ izhodiščni splošnoslovenski nenaglašeni, tj. kratki samoglasnik.

\section{Viri in literatura}

Braune, Wilhelm, Eggers, Hans, Althochdeutsche Grammatik, 14. Auflage bearbeitet von Hans Eggers, Tübingen ${ }^{14} 1987$ (1886).

Дыбо, Владимир Антонович, Славянская акиентология, Москва, 1981.

ДыБо, Владимир Антонович, Морфологизованные парадигматические акиентные системыл. Москва 2000.

Furlan, Metka, Slovensko slima 'Saliua, plouagne' (Alasia) in srbohrvaško slîm (Žumberek) - novo gradivo za slovansko-germansko izogloso *slimъ : *slìma-, Jezikoslovni zapiski 1, Ljubljana 1991, 25-30.

FuRLAN, Metka, Slovenščina v Alasijevem Italijansko-slovenskem slovarju iz leta 1607, Živeti mejo, Zbornik Slavističnega društva Slovenije 18, Uredil Miran Košuta, Ljubljana 2007, 290-306.

Grafenauer, Ivan, Poglavje iz najstarejšega slovenskega pismenstva I, Celovški rokopis., III, Očitna spoved Stiškega rokopisa, Časopis za slovenski jezik, književnost in zgodovino 8, Ljubljana 1931, 68-102, 106-117.

GRAFENAUER, Ivan, Slovenska slovstvena čitanka za višje razrede srednjih in sorodnih šol, Ljubljana 1942.

Grafenauer, Ivan, Nekaj novega o Rateškem (Celovškem) rokopisu. Jezik in slovstvo 1, Ljubljana 1955/56, 165-169.

GrafenAuer, Ivan, Celovški rokopis iz Rateč, podružnične beljaške prafare pri Mariji na Zilji, Razprave SAZU 3, Ljubljana 1958, 7-63.

JANKo, Anton, TeRŽAn-Kopecky, Karmen, Staronemško berilo / Altdeutsches Lesebuch, Ljubljana - Maribor ${ }^{3} 2000$. 
KREK, Gregor, O novoslovenskem rokopisu zgodovinskega društva koroškega, Kres 1, Celovec 1881, 173-190.

Logar, Tine, Dialektološke študije I: Narečna podoba zgornje savske doline, Slavistična revija 15, Ljubljana 1954, 145-149, Ponatis v Logar 1996, 40-43, Citirano po Logar 1996.

Logar, Tine, Današnje stanje in naloge slovenske dialektologije, Jezik in slovstvo 8, Ljubljana 1962-63, 1-6.

Logar, Tine, Pogorelec, Breda, Koruza, Jože, Starogorski rokopis iz konca 15. stoletja, Jezik in slovstvo 19, Ljubljana 1973/74, 192-211.

Logar, Tine, Pregled zgodovine slovenskega jezika, Seminar slovenskega jezika, literature in kulture, Ljubljana 1974. 103-113, Ponatis v Logar 1996, 331-336, Citirano po Logar 1996.

Logar, Tine, Izhodiščni splošnoslovenski fonološki sistem. Fonološki opisi srpskohrvatskih/ hrvatskosrpskih, slovenačkih i makedonskih govora obuhvaćenih opšteslovenskim lingvističkim atlasom. Ur. Pavle Ivić idr. Sarajevo 1981. 29-33. Ponatis v Logar 1996, 243-247.

Logar, Tine, Dialektološke in jezikovnozgodovinske razprave, Uredila Karmen Kenda-Jež, Ljubljana 1996.

Merkù, Pavle, Prehod - $t$ v - $u$ tržaški slovenščini. Slavistična revija 31/3, Ljubljana 1983, 260-262.

Miknailov, Nikolai, Früslowenische Sprachdenkmäler, Die handschriftliche Periode der slowenischen Sprache (XIV. Jh. bis 1550). Studies in Slavic and General Linguistics 26. Amsterdam, Atlanta 1998.

Mıкнailov, Nikolai, Jezikovni spomeniki zgodnje slovenščine, Rokopisna doba slovenskega jezika (od XIV. stol. do leta 1550), Trst 2001.

Ramovš, Fran, Historična gramatika slovenske jezika. II. Konzonantizem, Ljubljana 1924.

Ramovš, Fran, Kratka zgodovina slovenskega jezika. Ljubljana, 1936.

RAmovš, Fran, Relativna kronologija slovenskih akcentskih pojavov, Slavistična revija 3, Ljubljana 1950, 16-23.

Rigler, Jakob, Pregled osnovnih razvojnih etap v slovenskem vokalizmu. Slavistična revija 14. Ljubljana 1963, 25-78.

Rigler, Jakob, Pripombe k Pregledu osnovnih razvojnih etap v slovenskem vokalizmu, Slavistična revija 15, Ljubljana 1967, 1-2, 129-152.

Rigler, Jakob: Akcentske variante I, Slavistična revija 18, Ljubljana 1970, 5-15.

RigLER, Jakob: Akcentske variante II, Slavistična revija 19, Ljubljana 1971, 1-12.

RigLeR, Jakob, K problematiki daljšanja starega akuta, Slavistična revija 25, Ljubljana 1977, 83-99.

RigleR, Jakob, Akcentske variante III. Slavistična revija 26, Ljubljana 1978. $365-$ 374.

SchÜtzeichel, Rudolf, Althochdeutsches Wörterbuch, Tübingen ${ }^{5} 1995$ ('1969).

Stang, Christian S., Slavonic Accentuation, Oslo 1957.

$S S=$ Старославянский словарь (по рукописям $X-X I$ веков). Под редакцией Р. М. Цейтлин, Р. Вечерки и Э. Благовой Москва ${ }^{2} 1999$.

ToporišǏ́, Jože, Slovenski knjižni jezik 1, Ljubljana 1965. 
- Toporišıč, Jože, Enciklopedija slovenskega jezika., Ljubljana 1992.

[-] TOPORIšIČ, Jože, Stiški rokopis, Ljubljana 1992.

N Toporıšı̌č, Jože, Slovenski jezik in spročanje 1, Ljubljana 1994.

Toporıšı̌č, Jože, Slovenski jezik v času, Slovenska slovnica, Maribor ${ }^{4} 2000$ ('1976), 751-822.

\section{Dialect Base of the Language of the Klagenfurt/Celovec Manuscript and the Origin of the Form seydi}

Summary

The phonological system of the language of the Klagenfurt/Celovec Manuscript (KM, 1362-90) reflects the characteristics of the Upper Carniolan dialect base: 1) in the long vowel system, the Upper Carniolan-type early monophthongization of original SE Slovenian diphthongs occurred (the diphthong $e i$ is preserved in the morphologically isolated archaic aorist form $<$ seydi $>$ ): PSIn. $*^{*} / *_{\bar{o}}>$ SE Sln. $\left.*_{e i} / *^{*} \mathrm{ou}>\mathrm{KM}<\mathrm{e}>\mid<\mathrm{o}>; 2\right)$ in the short vowel system, the initial phase of Slovenian modern vocalic reduction can be observed: PSln. $*_{o}>\mathrm{KM}<\mathrm{u}>$; PSln. $*_{i} / *^{2}>\mathrm{KM}$ $<\mathrm{i}, \mathrm{y}>*[\mathrm{i}],<\mathrm{e}>*[\mathrm{\theta}]$; and 3 ) in the consonant system, the beginning of the simpli-

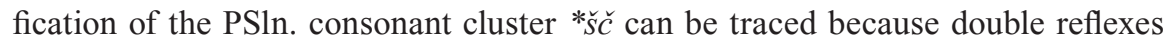
occur (i.e., a simplified and non-simplified consonant cluster): PSln. ${ }_{S \check{S} c}>\mathrm{KM}$ $<\int \mathrm{t} \int \mathrm{ch}>*[\check{s} \check{c}],<\iint \mathrm{ch}, \int \mathrm{ch}>*[\check{s} \check{s}] / *[\check{s}]$. The postulated phonological characteristics of the Gail/Zilja Valley and Lower Carniolan dialects can also be explained in terms of the Upper Carniolan dialect base. This fact calls into question Grafenauer's theory on the manuscript's language as a dialect mixture.

The Klagenfurt/Celovec Manuscript verbal form $<$ eydi $>$ reflects the 3rd person singular of the sigmatic aorist of the PSl. verb *sědě́ti *sédišb 'to sit' (KM < eeydi > = seìdi $<$ PSln. *sédě < Psl. *sědë '(he) sat'). The unusual use of the verbal aktionsart in this context in Slovenian (i.e., use of a verb of state instead of a verb of motion) can be ascribed to the morphosyntactic influence of the Old High German original (OHG gisaz '(he) sat; (he) sat down').

Matej Šekli

Oddelek za slavistiko

Filozofska fakulteta Univerze v Ljubljani

Aškerčeva 2, 1000 Ljubljana

Inštitut za slovenski jezik Frana Ramovša ZRC SAZU

Novi trg 2, 1000 Ljubljana

matej.sekli@guest.arnes.si 